\title{
Shifting demographic conflicts across recruitment cohorts in a dynamic post-disturbance landscape
}

\author{
Alexandro B. Leverkus, ${ }^{1,3}$ José María Rey Benayas, ${ }^{2}$ and Jorge Castro ${ }^{1}$ \\ ${ }^{1}$ Departamento de Ecología, Facultad de Ciencias, Universidad de Granada, E-18071, Granada, Spain \\ ${ }^{2}$ Departamento de Ciencias de la Vida, UD Ecología, Universidad de Alcalá, Edificio de Ciencias, 28805, Alcalá de Henares, Spain
}

\begin{abstract}
Seed dispersal effectiveness, which measures the number of adult plant individuals produced by seed dispersal, is the product of the number of seeds dispersed and the probability a seed produces an adult. Directed dispersal to certain habitat types may enhance some stages of recruitment but disfavor others, generating demographic conflicts in plant ontogeny. We asked whether temporal changes in habitat features may affect the distribution of seedlings recruited from dispersed acorns, and whether this could induce shifts in the life-stage conflicts experienced by successive cohorts of naturally recruited plants. As early successional habitats are characterized by rapid change, we used a burnt pine stand in southern Spain to monitor the recruitment and performance of a major tree species (Quercus ilex) across $7 \mathrm{yr}$ in four types of post-fire habitats. These differed in structure and included patches of unburnt forest and three management alternatives of burnt trees: logging, partial cutting, and nonintervention. Young oaks that resprouted after the fire were mainly located near acorn sources, while new seedlings initially emerged mostly in habitats with standing snags due to habitat selection by European jays, Garrulus glandarius, for dispersal. The dead pines gradually collapsed and attracted less dispersal, so subsequent seedling cohorts mainly recruited within patches of unburnt pines. These live pines enhanced the survival of the oaks located beneath their canopy but greatly reduced their growth as compared to the other post-fire habitats, thus representing a demographic conflict that was absent elsewhere. As a consequence of the directional shift in the habitat where seedlings recruited, successive seedling cohorts experienced a gradual improvement in their likelihood of survival but a reduction in growth. The progressive intensification of this life-stage conflict hinged on the reduction of vertical structures in the habitat with standing burnt pines. Recruitment success thus involved temporal variation in the habitat where recruitment occurred, likely resulting from changes in the direction of seed dispersal, and spatial variation in habitat suitability for seedling establishment and growth. Temporal changes in habitat structure can indirectly change the environment in which recruitment occurs, and consequently seed dispersal effectiveness, by shifting the direction of seed dispersal.
\end{abstract}

Key words: biological legacy; Garrulus glandarius; Holm oak; life-stage conflict; ontogeny; pine plantation; plant demography; post-fire succession; Quercus ilex; seed dispersal.

\section{INTRODUCTION}

Plant recruitment requires the transition of individuals across several ontogenetic stages, each of which can be affected by multiple interacting biotic and abiotic factors (Harper 1977, Fenner and Thompson 2005). Spatial variability in such factors, also named structural heterogeneity (Gómez et al. 2004), generates a matrix with variable conditions that may affect the probability of individuals becoming adults across the landscape. However, through nonrandom demographic processes, the environment in which recruitment actually occurs may encompass only a subset of the overall available conditions - this is referred to as functional heterogeneity (Gómez et al. 2004). Directed seed dispersal by animals skews the initial seed kernel towards certain habitats or

Manuscript received 7 March 2016; revised 18 June 2016; accepted 27 June 2016. Corresponding Editor: G. A. Fox.

33-mail: leverkus@ugr.es habitat elements (Janzen 1970, Dennis et al. 2007), and the environmental parameters that affect subsequent demographic processes are those that characterize these habitats (Schupp and Fuentes 1995).

The way in which animal-mediated seed dispersal affects plant demography can be described with the seed dispersal effectiveness (SDE) concept (Schupp et al. 2010). SDE is a measure of the amount of adult plant individuals that result from seed dispersal, and it encompasses a quantitative component (the amount of seeds that are dispersed), and a qualitative component (the probability of a seed producing a new adult) (Schupp et al. 2010). In relation to the qualitative component, earlier notions of "safe sites" for recruitment (Harper 1977) have been replaced by the understanding that different demographic stages may be affected by habitats in contrasting ways, potentially leading to life-stage conflicts (Schupp 1995, 2007, Pérez-Ramos et al. 2012, Van Ginkel et al. 2013). Further, each habitat type may induce 
distinctive life-stage conflicts within the landscape (Jordano and Herrera 1995, Schupp 1995, Gómez 2004, Pulido and Díaz 2005, Pérez-Ramos et al. 2012), resulting in a matrix where diverse demographic conflicts occur in different habitat patches. Ultimately, habitats may receive different densities of seed rain and result in different likelihoods of producing adult individuals (Louda 1983, Herrera et al. 1994, Schupp 1995, Schupp and Fuentes 1995, Pulido and Díaz 2005).

The effect of habitats on plant demography can vary with time, as the existence, magnitude and direction of life-stage conflicts are known to change (Schupp 2007). Without explicit consideration of temporal variability, the effects of habitats on demographic processes may be obscured as a result of averaging across different years (Schupp and Fuentes 1995). So far, temporal changes have been described as oscillations, chiefly arising from fluctuating weather conditions (Wenny 2000, GómezAparicio et al. 2004, Quero et al. 2011) or herbivore abundance (Gómez and Hódar 2008), and potential directional changes have been overlooked. As a result, we still know little about how temporal changes in dynamic habitats may translate into different habitat suitabilities for recruitment and potentially into different conflicts across plant ontogeny for successive recruitment cohorts. Increasing our knowledge of such processes may help us better understand the complexities of plant recruitment in rapidly changing habitats.

The initial years after severe disturbances are characterized by highly dynamic ecosystem processes, several of which occur directionally. Rapidly changing conditions include abiotic components involved in seedling establishment, such as light or nutrient availability (DeLuca et al. 2002, Ward et al. 2014), and biotic components such as competition or habitat selection by seed dispersers and predators (Keith and Bradstock 1994, Dafni et al. 2012). In particular, modifications in post-disturbance habitat structure can affect the abundance and habitat selection of seed-dispersing birds (Lain et al. 2008, Rost et al. 2009), and consequently change the spatial distribution of the seed rain (Rost et al. 2009, Cavallero et al. 2013). As post-disturbance habitats are spatially heterogeneous due to the presence, type and abundance of biological legacies (Franklin et al. 2000, Noss et al. 2006, Lindenmayer et al. 2008, Peterson et al. 2009), potential changes in the direction of seed dispersal may result in shifts in the functional environment and ultimately cause directional changes in the demographic processes that define SDE across subsequent cohorts of recruitment. However, to the best of our knowledge, such directional changes have not yet been described.

In this study, we asked whether ongoing changes in the structure of certain habitats during secondary succession following fire may yield directional shifts in the demographic conflicts experienced by successive cohorts of recruitment through directional changes in the habitat where seedlings recruit after seed dispersal. For this, we monitored the recruitment of a dominant tree species (the Holm oak, Quercus ilex L.) across 7 consecutive yr in a heterogeneous post-fire landscape whose habitat structure changed sharply through time. Four distinct habitat types were experimentally created in this landscape, consisting of unburnt patches of pines and three post-fire management treatments that modified habitat structure. It is well known that European jays (Garrulus glandarius), the main acorn dispersers in the study area (Castro et al. 2010), strongly select habitat characteristics for dispersal (Bossema 1979, Mosandl and Kleinert 1998, Gómez 2003), and they have previously shown to positively select habitats with standing burnt trees for seed caching (Castro et al. 2012). Thus, we hypothesized that (1) the emergence of oak seedlings resulting from dispersed acorns would be favored in postdisturbance habitats with standing trees. As the habitats generated different abiotic conditions and oak seedlings show enhanced survival under moderate shade due to the alleviation of hot and dry summer conditions in Mediterranean-type ecosystems (Zavala et al. 2000, Gómez 2004, Puerta-Piñero et al. 2007), we also hypothesized that (2) seedling survival would be higher in habitats with a surviving canopy cover. Shade, if excessive, may limit the growth and development of Holm oak seedlings (Zavala et al. 2000, Gómez et al. 2004, Espelta et al. 2005), so we hypothesized that (3) post-disturbance habitats with a dense shade would reduce the growth of the surviving seedlings. Further, we expected (4) the resulting demographic patterns of the different cohorts of post-fire Holm oak seedlings to be a function of the temporally variable contribution of the existing habitats to functional habitat attributes. This study should reveal whether seed dispersal effectiveness could show directional shifts due to changes in habitat characteristics through succession.

\section{Methods \\ Study site}

The study was carried out in the Sierra Nevada Natural Park (SE Spain), where in September 2005 the Lanjarón fire burned $\sim 1,300$ ha of 35-45 yr-old pine afforestations. An experimental plot of 17.8 ha was established at $1477 \mathrm{~m}$ a.s.l. in the burnt pine stand $\left(37^{\circ} 57^{\prime} \mathrm{N}, 3^{\circ} 29^{\prime} \mathrm{W}\right)$. At this elevation, Holm oak forests are considered the climax vegetation according to edaphic and climatic conditions as well as historical records (Valle 2003). The pine species present were Pinus pinaster and P. nigra, two native species that do not grow naturally in the area and lack resprouting capacity. Shrublands and patches of almond and chestnut orchards dominated the area surrounding the experimental plot, including scattered individuals and small clusters of mature Holm oak trees that did not burn (Fig. 1). The plot was SW-oriented and had an average slope of $30.3 \%$ and micaschist as bedrock. Climate in the area is typical Mediterranean, with warm, dry summers and mild, rainy winters. Mean annual rainfall is $501.1 \pm 48.8 \mathrm{~mm}(1988-2011$; values are 


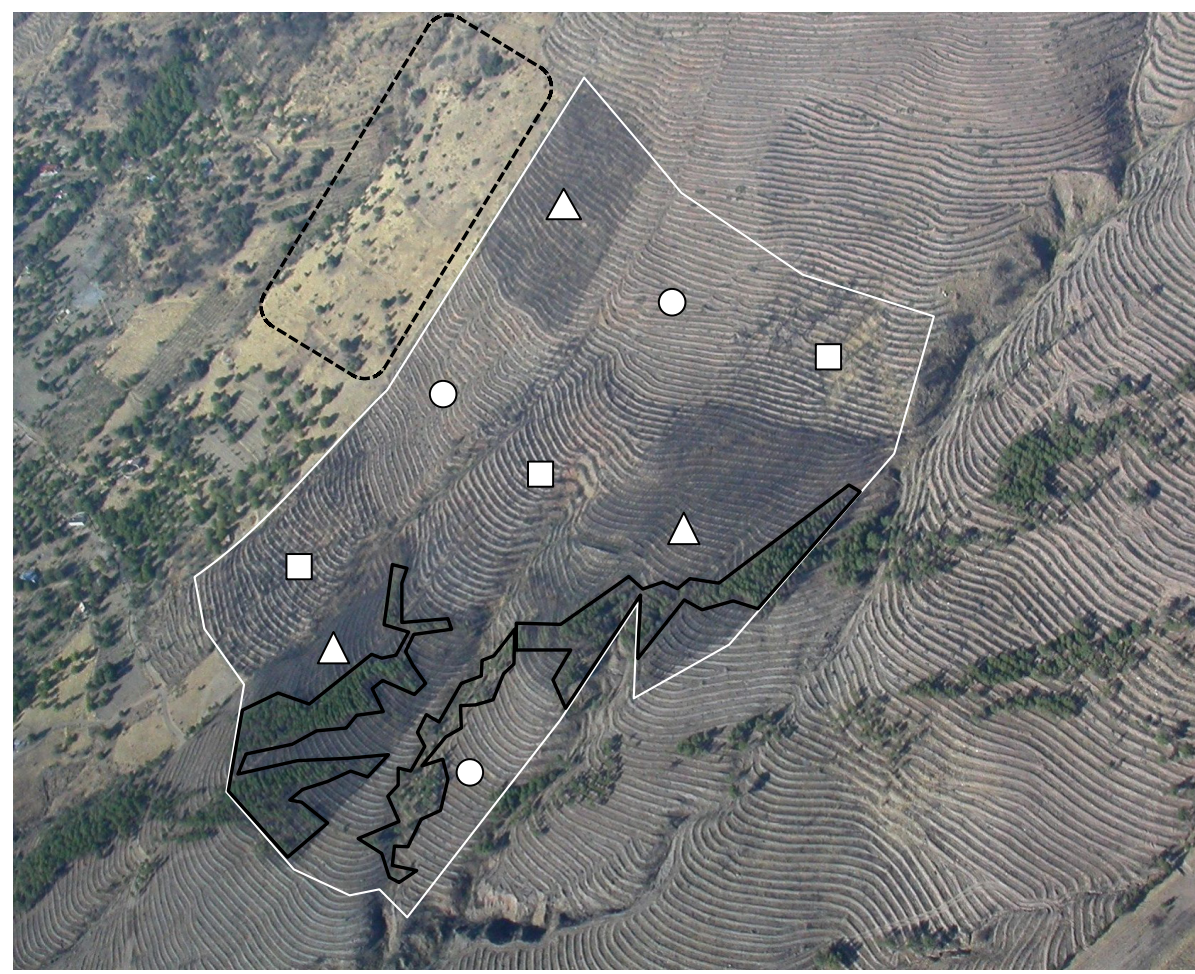

FIG. 1. Aerial view of the study plot, delimited by the white line, in 2006 (1 year after the fire). Triangles are located on the replicates of the nonintervention habitat, squares on the partial cut plus lopping habitat, and circles on the salvage logging habitat. The polygons delimited in black are the patches of surviving pines (the PIN habitat), and the dotted black polygon at the upper left side indicates the location of unburnt Holm oaks acting as seed sources. The parallel lines visible on the ground are terraces perpendicular to the slope, made to ease reforestation some $45 \mathrm{yr}$ previous to the study. All the terraced area was covered by a homogeneously aged pine stand before the fire, and the burnt pines beyond the plot boundaries were salvage/sanitation logged. Each side of the plot was $\sim 450 \mathrm{~m}$ long. Photo courtesy of the Sierra Nevada National Park. [Color figure can be viewed in the online issue, which is available at wileyonlinelibrary.com.]

mean $\pm 1 \mathrm{SE}$ throughout the text), of which only $4.7 \pm 1.3 \mathrm{~mm}$ correspond to July-August. Mean yearly minimum and maximum temperatures are $6.8 \pm 0.2^{\circ} \mathrm{C}$ and $17.1 \pm 0.2^{\circ} \mathrm{C}$, respectively $(1981-2010)$.

\section{Experimental design}

In April 2006, nine adjacent subplots of $2.0 \pm 0.2$ ha were established in collaboration with the local Forest Service (Fig. 1). Each subplot was randomly assigned to one of three replicates of one of three post-fire management treatments differing in habitat structure. Some patches of surviving pines covered $\sim 1.5$ ha across three of these subplots and were left standing (Fig. 1). These patches of surviving pines generated distinctive elements within the landscape, so we considered them as a fourth habitat type. As a result, there were three replicates of each of the following four post-fire habitats:

1. Non-intervention (NI): no action was taken, thus leaving a dense stand of standing burnt trees.

2. Partial cut plus lopping (PCL): $\sim 90 \%$ of the burnt trees were felled, with their main branches lopped off but leaving all the cut biomass in situ, spread over the ground. The logs and branches initially covered some $45 \%$ of the ground surface (Castro et al. 2011).

3. Salvage logging (SL): all the burnt trees were cut and cleared of their branches with chainsaws. The trunks were piled in groups of 10-15, and the woody debris was mechanically masticated. This produced an open landscape devoid of coarse woody debris except for the trunk piles.

4. Surviving Pines (PIN): Patches of pines that survived the fire and were left unlogged.

Pine density $(1,477 \pm 46$ individuals/ha, counted in 36 quadrats of $25 \times 25 \mathrm{~m}$ ) and basal trunk diameter $(17.7 \pm 0.2 \mathrm{~cm}$, estimated from 30 random trees per quadrat, thus 120 trees per subplot) were homogeneous across the whole plot before treatment implementation (Castro et al. 2012, Leverkus et al. 2014). The treatments created four habitats that differed in vertical structure, a parameter that exerts a strong effect on the foraging behavior of the European jay (Gómez 2003, Castro et al. 2012). Moreover, the burnt trees in the NI and PCL habitats collapsed during the course of our study period, mostly during the winters. The cumulative fall rate of burnt trees, always estimated in February, added up to 
$0.0 \%$ in 2006 and $2007,13.3 \pm 0.3 \%$ in $2008,83.5 \pm 4.0 \%$ in $2009,98.3 \pm 1.0 \%$ in 2010 and $100 \%$ thereafter (Molinas-González et al., unpublished manuscript). This induced yearly changes in the vertical structure of these habitats until 2010, when the last snags collapsed. Previous research, conducted when most of the burnt trees in NI still remained standing, showed that jays dispersed acorns from the unburnt Holm oaks into the subplots after the fire, preferentially into the NI habitat (Castro et al. 2012). Flights to the patches of unburnt pines were not monitored in this study, but the positive selection of pine forest by European jays for acorn dispersal is well established (Mosandl and Kleinert 1998, Gómez 2003).

The nearest group of Holm oaks acting as seed sources was located $40-450 \mathrm{~m}$ away from any part of the plot, which is a reasonable distance for dispersal by jays (Gómez 2003, Pons and Pausas 2007) but too far for dispersal by rodents (Gómez et al. 2008). Besides, rodents appear to act primarily as acorn consumers rather than dispersers in the area (Gómez et al. 2008), so here we assume that all the seedlings established after post-fire management (see details below) resulted from dispersal by jays.

\section{Seedling recruitment}

We monitored the recruitment of $Q$. ilex seedlings between spring and early summer of 2006 through 2012 by exhaustively searching the ground surface of the plot, tagging each individual seedling and taking their GPS coordinates. We monitored seedling survival and measured stem height, base diameter, and crown diameter in April 2012.

The seedlings that established each spring were assumed to correspond to acorns dispersed during the previous autumn. However, Holm oaks have a strong resprouting capacity (Zavala et al. 2000), so that the seedlings found in 2006 corresponded either to dispersal in autumn 2005 (i.e., after the fire but before treatment establishment) or to resprouting seedlings that were present in the understory before the fire. As we could not unequivocally distinguish these two origins, we labeled them all as premanagement seedlings. Some resprouting stems were fairly tall and clearly produced by an adult individual. As in this study we were interested in the recruitment dynamics at the seedling/sapling stage, we did not consider large resprouts and restricted the tagging to those individuals $<35 \mathrm{~cm}$ tall at the time of first sampling. All the seedlings encountered from 2007 onwards were labeled as postmanagement seedlings.

\section{Solar irradiance}

To characterize the post-fire habitats in terms of solar irradiance we took hemispheric photographs at $0.4 \mathrm{~m}$ above the ground. We used a horizontally leveled Canon Digital SLR camera with a Sigma $4.5 \mathrm{~mm} \mathrm{f/2.8} \mathrm{EX} \mathrm{DC}$
HSM circular fisheye lens. Photos were taken at dawn on the 20th and 27th of May 2014, by when all the snags had fallen. We took 30 photographs at random locations beneath the canopy of live pines in the PIN habitat and another 30 photographs outside; for the ones outside the canopy we considered 10 locations in SL, 10 in PCL, and 10 in NI. From the images, we obtained values of Global Site Factor (GSF) — which combines year-round direct and indirect solar radiation-with HemiView version 2.1.1 (Delta-T Devices Ltd., Cambridge, UK).

\section{Statistical analyses}

We first analyzed the effect of post-fire habitats on solar irradiance (GSF) with one-way ANOVA and compared between-habitat differences with Tukey HSD tests.

To test $H_{1}$, we analyzed the effect of post-fire habitats on seedling recruitment across successive cohorts. We analyzed the effects of habitat on the spatial distribution of oak seedlings by fitting point process models with the spatstat $\mathrm{R}$ package (Baddeley and Turner 2005). The models considered a nonhomogeneous Poisson process, with seedling density depending on post-fire habitat. This variable was included as a spatial covariate, with a raster image of the plot of $1 \times 1 \mathrm{~m}$ pixels containing different values for each of the four post-fire habitats. The performance of this model was compared through analysis of deviance with a similar model that considered a homogeneous distribution. This procedure was performed for (1) all seedlings together, (2) the premanagement seedlings only, (3) all postmanagement seedlings together, and (4) each cohort of postmanagement seedlings independently (2007-2012).

To test $\mathrm{H}_{2}$ we studied the effect of post-fire habitat on seedling survival by fitting generalized linear models (glm) with a binomial error structure (quasi-binomial to account for over-dispersion) for each cohort separately. The significance of the habitat factor was studied with analysis of deviance. The significance of individual contrasts between habitats was analyzed by merging levels of the habitat factor, rerunning the model and comparing the two models (Crawley 2013). The cohorts of 20062009 were analyzed at this stage.

To test $\mathrm{H}_{3}$ we analyzed the effect of post-fire habitat on seedling growth with one-way ANOVA. The response variables were the size values obtained in 2012 for stem height, base diameter, and mean crown diameter. We report the data of seedlings of the cohorts recruited from 2006 to 2009. $H_{4}$ is addressed throughout the methods.

All analyses were carried out in $\mathrm{R}$ version 3.1.1 ( $\mathrm{R}$ Core Team, 2014).

\section{RESUlTS}

\section{Solar irradiance}

Post-fire habitat significantly affected solar irradiance $\left(F_{3,56}=96.9 ; P<0.001\right)$. The GSF values under the canopy of surviving pines $(0.42 \pm 0.03 \%)$ were less than 


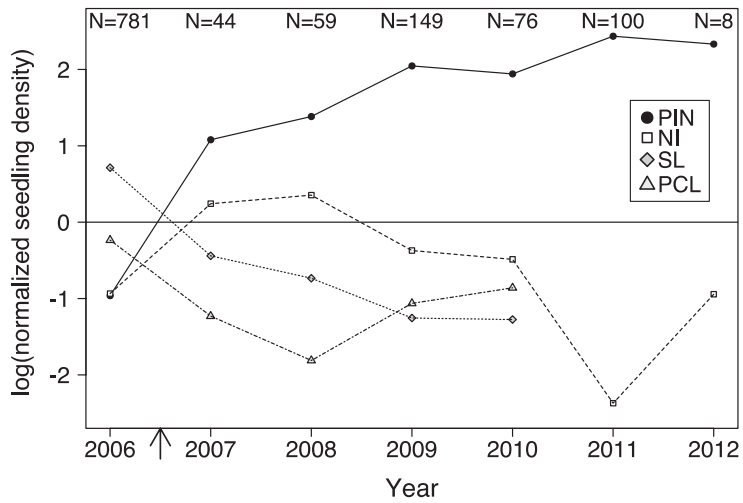

FIG. 2. Normalized seedling density in the post-fire habitats for the recruitment cohorts of 2006-2012 (the fire occurred in 2005). Data points show the logarithm of the seedling density found in a given habitat and year divided by the average seedling density across habitats in that year (the latter is indicated by the horizontal line at $y=0$ ). There was no recruitment in the SL and PCL habitats in 2011 and 2012. Values at the top are the number of seedlings recruited each year across the study area. The arrow under the $X$ axis shows the timing of post-fire management. Note the change in the distribution of seedling recruitment among habitats from 2006 (premanagement seedlings) to 2007 (postmanagement seedlings). Post-fire habitats were: PIN, pines (patches of pines that survived the fire and were left standing); NI, non-intervention; SL, salvage logging; PCL, partial cut plus lopping.

half than in any other habitat type $(0.94 \pm 0.01 \%$ on average). However, there were no differences in GSF among the NI, SL and PCL habitats.

\section{Spatio-temporal patterns of seedling recruitment}

We found a total of 1,223 Holm oak seedlings across the $7 \mathrm{yr}$ of study, which resulted in an average of 71.9 seedlings/ha. Of these, $64 \%$ were premanagement seedlings (including post-fire resprouts, which likely constituted the largest fraction). Seedling recruitment in subsequent years ranged between a total of 8 and 149 seedlings per year across the study site (Fig. 2).

The overall spatial pattern of oak seedlings, including both premanagement and postmanagement seedlings, was not homogeneous, as the model considering a nonhomogeneous Poisson distribution with post-fire habitat as covariate performed significantly better than a model with a homogeneous distribution $\left(\chi^{2}=520.46, P<0.001\right)$. The

FIG. 3. Kernel-smoothed seedling densities encountered in the study area for (a) premanagement seedlings, (b) postmanagement seedlings, and (c) all seedlings combined. The maps show the intensities of the point pattern generated by seedlings within the plot. The change in the overall spatial pattern of recruitment between pre- and postmanagement seedlings is evidenced by comparing maps (a) and (b). A portion of Replicate 2 of salvage logging was removed from sampling (and thus from the study) due to very high densities of premanagement seedlings, likely resprouts. The tree at the top of panel (a) shows the approximate position of the unburnt, acornproducing holm oaks (Fig. 1). [Color figure can be viewed in the online issue, which is available at wileyonlinelibrary.com.] nonhomogeneous model also performed best when analyzing the seedlings of each cohort separately. However, the direction and magnitude of the spatial pattern of recruitment changed over time. The 2006 (premanagement) seedlings were mainly encountered near the main acorn sources, as $61 \%$ of them were located in the three subplots that were closest to the unburnt patches of mature oaks (Fig. 3a). The NI and PIN habitats were associated
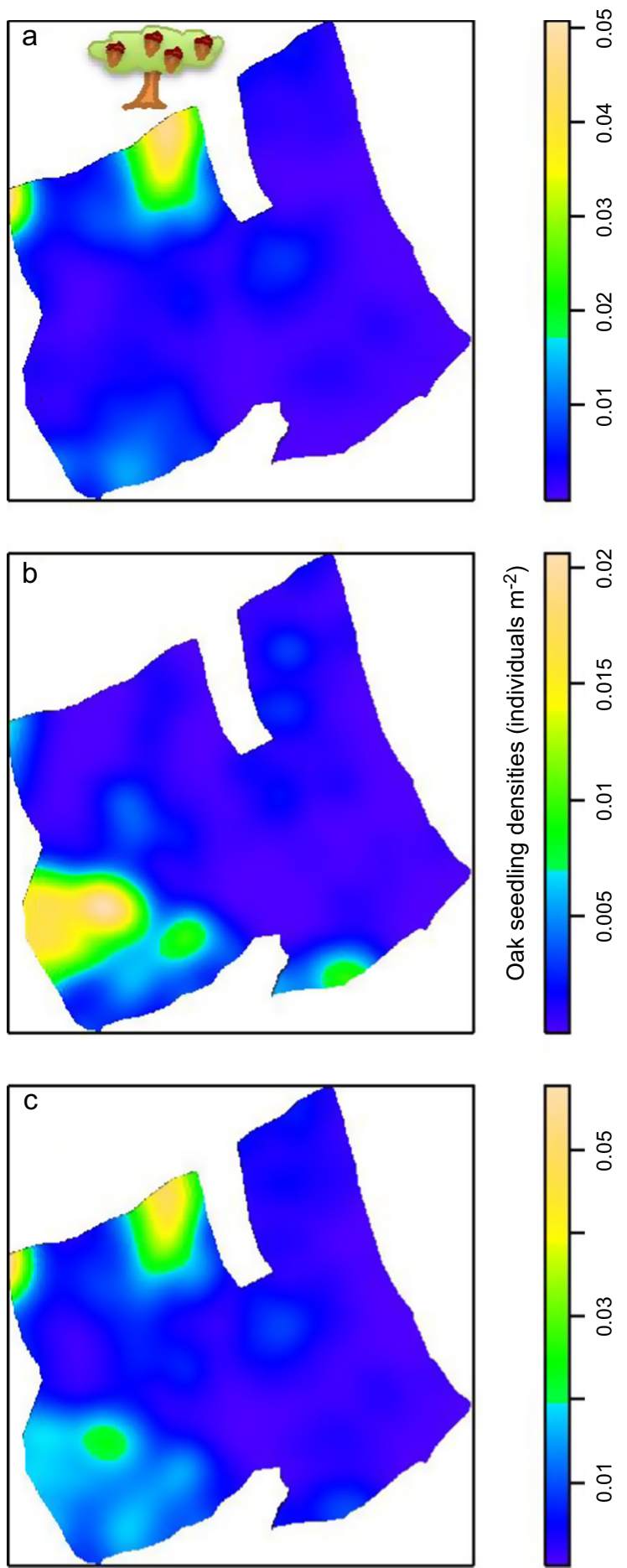
TABLE 1. Effect of post-fire habitats on the density of Holm oak seedlings encountered each year.

\begin{tabular}{|c|c|c|c|c|c|c|c|c|c|}
\hline \multirow[b]{3}{*}{ Seedling cohort } & \multirow[b]{3}{*}{$N$} & & & \multicolumn{6}{|c|}{ Contrasts with NI } \\
\hline & & \multicolumn{2}{|c|}{ Post-fire habitat $\dagger$} & \multicolumn{2}{|c|}{ PIN } & \multicolumn{2}{|c|}{ SL } & \multicolumn{2}{|c|}{ PCL } \\
\hline & & $\chi^{2}$ & $P$ & $Z$-value & $P$ & $Z$-value & $P$ & $Z$-value & $P$ \\
\hline 2006 & 781 & 415.98 & $* * *$ & 1.04 & & 16.10 & $* * *$ & 5.82 & $* * *$ \\
\hline $07-12$ & 442 & 748.67 & $* * *$ & 18.93 & $* * *$ & -3.06 & $* *$ & -5.17 & $* * *$ \\
\hline 2007 & 41 & 17.52 & $* * *$ & 1.62 & & -1.09 & & -2.74 & $* *$ \\
\hline 2008 & 58 & 51.88 & $* * *$ & 3.46 & $* * *$ & -2.20 & $*$ & -3.51 & $* * *$ \\
\hline 2009 & 159 & 240.37 & $* * *$ & 10.50 & $* * *$ & -1.99 & $*$ & -2.65 & $* *$ \\
\hline 2010 & 76 & 106.93 & $* * *$ & 7.45 & $* * *$ & -1.14 & & -1.07 & \\
\hline 2011 & 100 & 386.62 & $* * *$ & 7.77 & $* * *$ & 0.29 & & -0.01 & \\
\hline 2012 & 8 & 28.62 & $* * *$ & 2.93 & $* *$ & 0.00 & & 0.00 & \\
\hline
\end{tabular}

* $P<0.05 ; * * P<0.01 ; * * * P<0.001$

$\dagger$ Habitats were: NI, non-intervention; PIN, surviving pines; SL, salvage logging; PCL, partial cut plus lopping.

with significantly lower premanagement seedling densities than SL or PCL (Table 1; note though that this result is a statistical artifact, as the treatments were applied after the emergence of these seedlings; this is reported only for comparison between the spatial patterns of premanagement and postmanagement seedlings).

Once the post-fire habitats were established, the spatial distribution of newly recruited oak seedlings changed dramatically. The density of all postmanagement seedlings, which emerged between 2007 and 2012, was lowest in the SL and PCL subplots and greatest in PIN (Table 1, Figs. 2, 3b) despite the latter being the furthest away from the seed sources (Fig. 1). Moreover, the effect of post-fire habitat on seedling recruitment also changed over time for postmanagement seedlings. The NI habitat exerted a positive effect on oak seedling recruitment compared to the PCL and/or SL habitats in the first years after post-fire management (2007-2009; Table 1), but there was no significant difference among these three habitats after 2009. From 2008 onward, the density of newly recruited seedlings was significantly greater in the PIN than in the NI, PCL or SL habitats (Table 1, Fig. 2). The magnitude of this effect consistently increased until 2011-2012, when the density of newly recruited oak seedlings under live pines was one order of magnitude greater than in the rest of the area (Fig. 2). As a result, the study site ended up having different clusters of recruited oaks, some due to the existence of oak seedlings that survived the fire and others recruited after post-fire seed dispersal (Fig. 3c).

\section{Effect of post-fire habitat on seedling survival and growth}

Post-fire habitat significantly affected the survival of recruited seedlings encountered in 2006 and 2008 but not in 2007 or 2009 (Table 2). For the 2006 and 2008 cohorts, the highest survival was underneath the canopy of the surviving pines (Fig. 4). For the 2008 cohort, the PCL habitat led to high survival too, although this result is based on only three individuals (Appendix S1: Table S1).

The PIN habitat had a negative effect on final stem diameter for the seedlings of each of the analyzed cohorts (2006-2009; Table 2, Fig. 4). The PIN habitat also negatively affected stem height and crown diameter for seedlings of all cohorts except 2008 (Table 2, Fig. 4; for means and significance of contrasts between habitats, See Appendix S1: Table S1).

\section{DisCUSSION}

We found heterogeneous Holm oak recruitment across the studied post-fire landscape as a result of

TABLE 2. Effect of post-fire habitat on Holm oak seedling survival and size in 2012.

\begin{tabular}{|c|c|c|c|c|c|c|c|c|c|c|c|c|}
\hline \multirow[b]{3}{*}{ Response var. } & \multicolumn{12}{|c|}{ Year of seedling encounter } \\
\hline & \multicolumn{3}{|c|}{2006} & \multicolumn{3}{|c|}{2007} & \multicolumn{3}{|c|}{2008} & \multicolumn{3}{|c|}{2009} \\
\hline & Df & $F$ & $P$ & df & $F$ & $P$ & $\mathrm{df}$ & $F$ & $P$ & $\mathrm{df}$ & $F$ & $P$ \\
\hline Seedling survival & 777 & 6.0 & $<0.001$ & 40 & 2.7 & 0.06 & 55 & 5.4 & $<0.01$ & 145 & 0.5 & 0.65 \\
\hline Stem diameter & 439 & 15.2 & $<0.001$ & 20 & 6.6 & $<0.01$ & 23 & 6.4 & $<0.01$ & 73 & 21.7 & $<0.001$ \\
\hline Stem height & 439 & 10.8 & $<0.001$ & 20 & 9.9 & $<0.001$ & 23 & 2.7 & 0.09 & 73 & 14.6 & $<0.001$ \\
\hline Crown diameter $\dagger$ & 439 & 18.4 & $<0.001$ & 20 & 6.9 & $<0.01$ & 23 & 1.7 & 0.21 & 73 & 16.4 & $<0.001$ \\
\hline
\end{tabular}

$\dagger$ Average of two perpendicular crown measurements. 
(a)
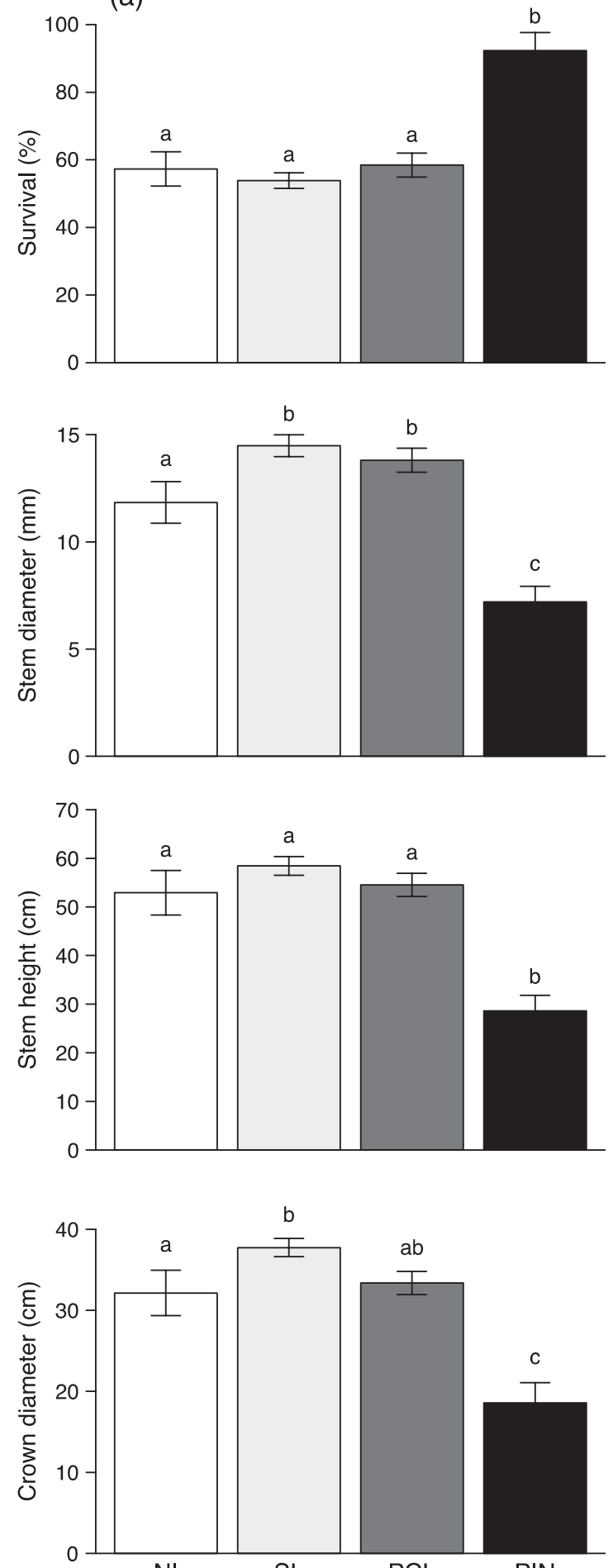

NI

SL

PCL

PIN

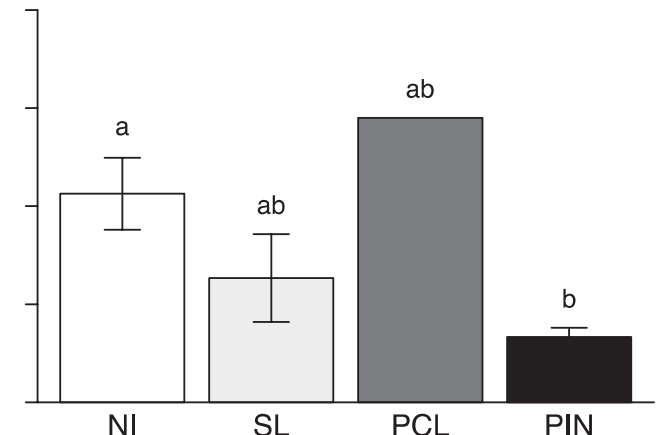

FIG. 4. Average survival and size (measured in 2012) of the Holm oak seedlings/saplings encountered in (a) 2006 and (b) 2007 across different post-fire habitats. While most of the 2006 oaks were likely resprouting individuals that were present before the fire, the 2007 seedlings emerged from acorns dispersed in 2006 and were 5-yr-old saplings at the time of measurement. Post-fire habitats are: NI, non-intervention; SL, salvage logging; PCL, partial cut plus lopping; PIN, surviving pines. Error bars indicate $\pm 1 \mathrm{SE}$ of the means. Letters above the bars indicate significant between-habitat differences after post-hoc tests at $P<0.05$. The values for these and the 2008 and 2009 seedling cohorts, as well as the number of individuals across habitats, can be found in Appendix S1: Table S1. 
spatiotemporal disparities in habitat features. The presence of live trees yielded high oak seedling recruitment throughout the study period, while the standing dead trees had a temporally limited positive effect on recruitment due to their gradual collapse. Most of the seedlings that recruited in early years showed moderate survival but adequate growth due to their location away from the canopy of surviving pines. In contrast, the seedlings located beneath these pines showed enhanced survival but reduced growth. Further, there was a gradual increase in the proportion of new recruits emerging beneath live pines throughout the study period. Our study thus suggests a directional shift in a major demographic conflict encountered by different recruitment cohorts.

\section{Spatial patterns of recruitment}

After a stand-replacing disturbance, biological legacies from the past ecosystem set the scene for plant regeneration (Franklin et al. 2000, Lindenmayer et al. 2008, Christensen 2014). In our study, two main kinds of post-fire legacies affected the densities of juvenile oaks. First, oak individuals that survived the fire and resprouted accounted for about two-thirds of the juvenile oaks that we found. Inherent to this legacy was the spatial distribution of the resprouts, which was strongly skewed towards the subplots located near the main acorn sources. This distribution was likely due to the important yet limited dispersal distances covered before the fire by
European jays, which are the main acorn dispersers in the area (Gómez 2003, Castro et al. 2010, 2012) and the Palearctic in general (Bossema 1979, Mosandl and Kleinert 1998, Pulido and Díaz 2005). As a consequence, oak seedling densities within pine plantations tend to decline nonlinearly with distance to mature oaks (GómezAparicio et al. 2009), and this was likely the baseline condition in our study area before the fire, when the landscape was composed of a uniform pine stand.

Secondly, standing live and dead pines also affected oak demography. Seed dispersal by European jays was still the main mechanism for colonization after the fire (Castro et al. 2012). As jays are forest dwellers (Bossema 1979, Pons and Pausas 2008), they tend to direct their dispersal towards areas with high tree cover, especially coniferous forest (Gómez 2003, Pons and Pausas 2007). Our results show that once heterogeneous habitats were created after post-fire management within the burnt plantation, oak seedling recruitment was positively associated to the habitats with standing live or dead trees. The standing trees attracted seed dispersal by jays (Castro et al. 2012), leading to patches of high oak densities far away from the acorn sources. This contrasts with the resprouts, which emerged from acorns dispersed mainly near acorn sources before the fire. As a consequence, there was a dramatic shift between the spatial distribution of resprouts and that of seedlings emerged after the creation of spatially heterogeneous post-fire habitat structures by the fire and subsequent management.
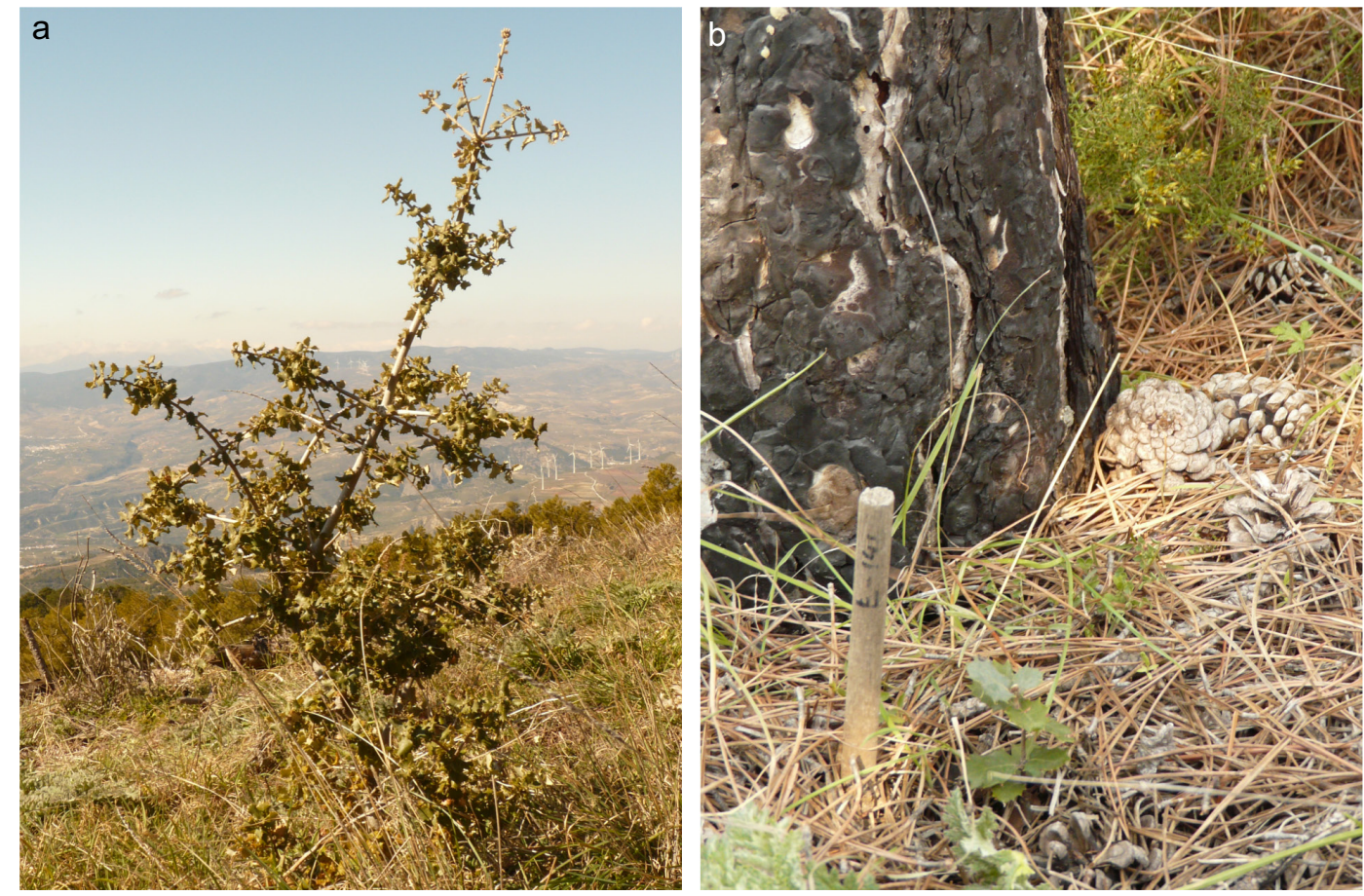

FIG. 5. Specimens of Holm oaks recruited after the fire in 2007 (a) in an open area and (b) under the canopy of pines that survived the 2005 fire. The photos were taken in 2013. [Color figure can be viewed in the online issue, which is available at wileyonlinelibrary.com.] 


\section{Temporal patterns of recruitment}

We observed a shift between the distribution of different cohorts of postmanagement seedlings, which derived from the different persistence in time of standing dead and live trees. The standing dead trees in the NI habitat had a similar positive effect on oak seedling recruitment as the live trees in PIN during the first years, but their gradual collapse led the positive effect of the NI habitat to decrease over time and ultimately vanish, which was likely the result of the vertical habitat structure preferred by jays disappearing (Castro et al. 2012). Another explanation is that the trees that collapsed generated a complex habitat structure that induced high levels of acorn predation by rodents (Leverkus et al. 2013, 2015), a major demographic filter for oak recruitment (Herrera 1995, Pulido and Díaz 2005, Gómez et al. 2008, Pérez-Ramos et al. 2012, Rey Benayas et al. 2015). The abundance and activity of rodents may have increased as a consequence of the protection provided by the lying logs (Puerta-Piñero et al. 2010, Leverkus et al. 2013, 2015). As a result, the collapse of the standing snags gradually reduced habitat suitability for acorn dispersers and enhanced the suitability for acorn consumers, thus triggering a directional reduction in the recruitment of oaks in the NI subplots. In contrast, the reduction of dispersal to NI may have had an indirect positive effect on dispersal to areas of live pines, where an increasingly greater proportion of seedlings emerged during and after the collapse of the dead trees.

\section{Ontogenetic conflicts}

The patches of live pines generally enhanced oak seedling survival but reduced their growth as compared to the rest of post-fire habitats. Greater survival was likely a result of alleviated summer temperatures under the canopy shade, as summer drought strongly limits oak seedling establishment and survival in Mediterranean landscapes (Rey Benayas et al. 2005, 2015, Castro et al. 2006, Gómez-Aparicio et al. 2008, Mendoza et al. 2009b, Pérez-Ramos et al. 2012). The amelioration of these conditions may lead to greater probabilities of survival, because it reduces evaporation, photoinhibition and the risk of carbon starvation in young Holm oak seedlings (Zavala et al. 2000, Rey Benayas et al. 2005). On the contrary, competition from adult pines had a negative influence on the growth of oak seedlings recruited beneath their canopy, as these seedlings were much smaller than those recruited elsewhere (Fig. 5). Dense pine stands are highly water demanding (Maestre and Cortina 2004), and water deficit beneath them can even be greater than outside their canopy under dry conditions (Valladares and Pearcy 2002). Dense pine stands also reduce light availability - in this study the pines reduced global solar irradiance to half. Thus, although the Holm oak is shade tolerant and benefits from moderate shade in its early life stages (Espelta et al. 1995, 2005, Zavala et al. 2000, Gómez 2004), the shade of dense canopies limits their growth (Espelta et al. 2005, Mendoza et al. 2009a). This tradeoff has also been found in other studies (Zavala et al. 2000, PérezRamos et al. 2012, Galiano et al. 2013).

\section{Implications for seed dispersal effectiveness}

Seed dispersal effectiveness, which measures the number of adult recruits produced by seed dispersal, comprises complex and interacting processes that affect plant recruitment. Temporal changes in such processes have been widely documented, providing insight into the unpredictability of recruitment success (Schupp 2007). However, these changes have chiefly been described as fluctuations, overlooking the directionality of many processes that occur at various temporal scales during secondary succession. Our study shows, on the one hand, a directional shift in the habitat where oak recruitment occurred along the first years of post-fire succession. On the other hand, the habitats where most of the initial recruits emerged were characterized by different conditions than the habitat where recruitment occurred at later stages. As a result, the functional environment experienced by successive cohorts of oak recruits experienced a directional shift too, which led to opposing changes in two demographic stages involved in the qualitative aspect of seed dispersal effectiveness: the survival and growth of seedlings (Schupp et al. 2010). This resulted in a shift in a major ontogenetic conflict experienced by seedlings and in the contribution of the involved demographic stages to seed dispersal effectiveness: from moderate survival but appropriate growth to enhanced survival yet deficient growth. This study highlights the importance of studying the processes that affect seed dispersal effectiveness and recruitment dynamics with explicit consideration of directional habitat modifications and at variable temporal scales, especially in the case of rapidly changing, early-successional habitats.

\section{Disturbance, succession and windows of opportunity for oak forest regeneration}

Tree plantations are globally recognized as habitats where natural succession is often arrested (Cannell 1999, Maestre and Cortina 2004, Brockerhoff et al. 2008, Gómez-Aparicio et al. 2009, Ruiz-Benito et al. 2012). In particular, pine plantations like the one studied here spread over thousands of hectares in the Mediterranean Basin, have a high risk of fire propagation, and thus represent management challenges (Maestre and Cortina 2004, Pausas et al. 2004a, b, Gómez-Aparicio et al. 2009). In such ecosystems, which are usually dominated by a dense, monospecific and even-aged stand, plants remaining as legacies of past ecosystems and processes mediated by seed dispersers offer an opportunity for succession (Gómez-Aparicio et al. 2009, Zamora et al. 2010, Navarro-González et al. 2013), provided that canopy gaps are opened at some stage to allow the competitive release of the understory and create a window of opportunity for the regeneration of oaks. Our study shows that 
oaks remaining as legacies and dispersal from nearby oaks may yield a high potential for the naturalization of the stand.

Beyond its consideration as a disturbance with large negative connotations, fire could act as the necessary mechanism for the colonization and persistence of oaks in such landscapes. Active policies of fire management (such as prescribed fires) in landscapes where both seed sources (mature oaks) and mutualistic organisms (jays) are present may provide the basis for the restoration of the original oak forests. Habitat heterogeneity, obtained by variable fire intensities and post-fire management techniques, and in other cases variable pre-fire conditions, may prove valuable to enhance different stages of tree recruitment in Mediterranean landscapes.

\section{Conclusion}

Shifting environmental conditions can affect plant demography not only through direct effects on individuals but also through modifications of the preferred habitat for seed dispersal and the resulting change in the relative contribution of habitats to the functional environment. Such changes can occur directionally, for example due to the loss of habitat patches preferred by the main seed dispersers or due to successional changes in the disperser community. This study highlights the importance of studying plant recruitment not only across different ontogenetic stages but also with explicit consideration of temporal habitat shifts in order to understand the mechanisms underlying plant recruitment, especially in rapidly changing environments such as forests shortly after disturbance.

\section{ACKNOWLEDGMENTS}

The Consejería de Medio Ambiente (Junta de Andalucía) and the Direction of the Natural and National Park of Sierra Nevada provided fieldwork permission, constant support and facilities. We are grateful to A. Sánchez, R. Ruiz, C. Serrano, C. Puerta, M. Molina, and A. López for fieldwork assistance. F.B. Navarro kindly allowed the use of the fisheye camera. Projects CGL2008-01671 and CGL2014-53308-P from the Spanish Ministry of Science and Innovation and S2009AMB-1783 "REMEDINAL-2" and S2013/MAE-2719 "REMEDINAL-3" from the Government of Madrid, as well as Ph.D. fellowship to AL (AP2010-0272) from the Spanish Ministry of Science and Education, supported this study. Dr. E.W. Schupp and an anonymous reviewer provided suggestions that enhanced this manuscript.

\section{Literature Cited}

Baddeley, A., and R. Turner. 2005. spatstat: an R package for analyzing spatial point patterns. Journal of Statistical Software 12:1-42.

Bossema, I. 1979. Jays and oaks: an eco-ethological study of a symbiosis. Behaviour 70:1-117.

Brockerhoff, E. G., H. Jactel, J. A. Parrotta, C. P. Quine, and J. Sayer. 2008. Plantation forests and biodiversity: Oxymoron or opportunity? Biodiversity and Conservation 17:925-951.
Cannell, M. G. R. 1999. Environmental impacts of forest monocultures: water use, acidification, wildlife conservation, and carbon storage. New Forests 17:239-262.

Castro, J., C. D. Allen, M. Molina-Morales, S. MarañónJiménez, Á. Sánchez-Miranda, and R. Zamora. 2011. Salvage logging versus the use of burnt wood as a nurse object to promote post-fire tree seedling establishment. Restoration Ecology 19:537-544.

Castro, J., G. Moreno-Rueda, and J. A. Hódar. 2010. Experimental test of postfire management in pine forests: impact of salvage logging versus partial cutting and nonintervention on bird-species assemblages. Conservation Biology 24:810-819.

Castro, J., C. Puerta-Piñero, A. B. Leverkus, G. MorenoRueda, and A. Sánchez-Miranda. 2012. Post-fire salvage logging alters a key plant-animal interaction for forest regeneration. Ecosphere 3:art90.

Castro, J., R. Zamora, and J. A. Hódar. 2006. Restoring Quercus pyrenaica forests using pioneer shrubs as nurse plants. Applied Vegetation Science 9:137-142.

Cavallero, L., E. Raffaele, and M. A. Aizen. 2013. Birds as mediators of passive restoration during early post-fire recovery. Biological Conservation 158:342-350.

Christensen Jr., N. L. 2014. An historical perspective on forest succession and its relevance to ecosystem restoration and conservation practice in North America. Forest Ecology and Management 330:312-322.

Crawley, M. J. 2013. The R book. Second edition. Wiley \& Sons, New Delhi, India.

Dafni, A., I. Izhaki, and G. Ne'eman. 2012. The effect of fire on biotic interactions in Mediterranean Basin ecosystems: pollination and seed dispersal. Israel Journal of Ecology \& Evolution 58:235-250.

DeLuca, T. H., M. C. Nilsson, and O. Zackrisson. 2002. Nitrogen mineralization and phenol accumulation along a fire chronosequence in northern Sweden. Oecologia 133:206-214.

Dennis A. J., E. W. Schupp, R. J. Green, and D. A. Wescott, editors. 2007. Seed dispersal: Theory and its application in a changing world. CAB International, Wallingford, UK.

Espelta, J. M., P. Cortés, M. Mangirón, and J. Retana. 2005. Differences in biomass partitioning, leaf nitrogen content, and water use efficiency $\left(\delta^{13} \mathrm{C}\right)$ result in similar performance of seedlings of two Mediterranean oaks with contrasting leaf habit. Ecoscience 12:447-454.

Espelta, J. M., M. Riba, and J. Retana. 1995. Patterns of seedling recruitment in West-Mediterranean Quercus ilex forests influenced by canopy development. Journal of Vegetation Science 6:465-472.

Fenner, M., and K. Thompson. 2005. The ecology of seeds. Cambridge University Press, New York, New York, USA.

Franklin, J. F., D. Lindenmayer, J. A. Macmahon, A. Mckee, D. A. Perry, R. Waide, and D. Foster. 2000. Threads of continuity. Conservation in Practice 1:8-17.

Galiano, L., J. Martínez-Vilalta, M. Eugenio, Í. Granzow-de la Cerda, and F. Lloret. 2013. Seedling emergence and growth of Quercus spp. following severe drought effects on a Pinus sylvestris canopy. Journal of Vegetation Science 24:580-588.

Gómez, J. M. 2003. Spatial patterns in long-distance dispersal of Quercus ilex acorns by jays in a hetereneous landscape. Ecography 5:573-584.

Gómez, J. M. 2004. Importance of microhabitat and acorn burial on Quercus ilex early recruitment: non-additive effects on multiple demographic processes. Plant Ecology 172:287-297.

Gómez, J. M., and J. A. Hódar. 2008. Wild boars (Sus scrofa) affect the recruitment rate and spatial distribution of holm oak (Quercus ilex). Forest Ecology and Management 256:1384-1389. 
Gómez, J. M., C. Puerta-Piñero, and E. W. Schupp. 2008. Effectiveness of rodents as local seed dispersers of Holm oaks. Oecologia 155:529-537.

Gómez, J. M., F. Valladares, and C. Puerta-Piñero. 2004. Differences between structural and functional environmental heterogeneity caused by seed dispersal. Functional Ecology 18:787-792.

Gómez-Aparicio, L., I. M. Pérez-Ramos, I. Mendoza, L. Matías, J. L. Quero, J. Castro, R. Zamora, and T. Marañón. 2008. Oak seedling survival and growth along resource gradients in Mediterranean forests: implications for regeneration in current and future environmental scenarios. Oikos 117:1683-1699.

Gómez-Aparicio, L., R. Zamora, J. M. Gómez, J. A. Hódar, J. Castro, and E. Baraza. 2004. Applying plant facilitation to forest restoration: a meta-analysis of the use of shrubs as nurse plants. Ecological Applications 14:1128-1138.

Gómez-Aparicio, L., M. A. Zavala, F. J. Bonet, and R. Zamora. 2009. Are pine plantations valid tools for restoring Mediterranean forests? An assessment along abiotic and biotic gradients. Ecological Applications 19:2124-2141.

Harper, J. L. 1977. Population biology of plants. Academic Press, London, UK.

Herrera, J. 1995. Acorn predation and seedling production in a low-density population of cork oak (Quercus suber L.). Forest Ecology and Management 76:197-201.

Herrera, C. M., P. Jordano, L. Lopez-Soria, and J. A. Amat. 1994. Recruitment of a mast-fruiting, bird-dispersed tree: bridging frugivore activity and seedling establishment. Ecological Monographs 64:315-344.

Janzen, D. H. 1970. Herbivores and the number of tree species in tropical forests. American Naturalist 104:501-528.

Jordano, P., and C. M. Herrera. 1995. Shuffling the offspring: uncoupling and spatial discordance of multiple stages in vertebrate seed dispersal. Ecoscience 2:230-237.

Keith, D. A., and R. A. Bradstock. 1994. Fire and competition in Australian heath: a conceptual model and field investigations. Journal of Vegetation Science 5:347-354.

Lain, E. J., A. Haney, J. M. Burris, and J. Burton. 2008. Response of vegetation and birds to severe wind disturbance and salvage logging in a southern boreal forest. Forest Ecology and Management 256:863-871.

Leverkus, A. B., J. Castro, C. Puerta-Piñero, and J. M. Rey Benayas. 2013. Suitability of the management of habitat complexity, acorn burial depth, and a chemical repellent for post-fire reforestation of oaks. Ecological Engineering 53:15-22.

Leverkus, A. B., J. Lorite, F. B. Navarro, E. P. Sánchez-Cañete, and J. Castro. 2014. Post-fire salvage logging alters species composition and reduces cover, richness, and diversity in Mediterranean plant communities. Journal of Environmental Management 133:323-331.

Leverkus, A. B., M. Rojo, and J. Castro. 2015. Habitat complexity and individual acorn protectors enhance the post-fire restoration of oak forests via seed sowing. Ecological Engineering 83:276-280.

Lindenmayer, D. B., P. J. Burton, and J. F. Franklin. 2008. Salvage logging and its ecological consequences. Island Press, Washington, D.C., USA.

Louda, S. M. 1983. Seed predation and seedling mortality in the recruitment of a shrub, Haplopappus venetus (Asteraceae), along a climatic gradient. Ecology 64:511-521.

Maestre, F. T., and J. Cortina. 2004. Are Pinus halepensis plantations useful as a restoration tool in semiarid Mediterranean areas? Forest Ecology and Management 198:303-317.

Mendoza, I., L. Gómez-Aparicio, R. Zamora, and L. Matías. $2009 a$. Recruitment limitation of forest communities in a degraded Mediterranean landscape. Journal of Vegetation Science 20:367-376.

Mendoza, I., R. Zamora, and J. Castro. 2009b. A seeding experiment for testing tree-community recruitment under variable environments: implications for forest regeneration and conservation in Mediterranean habitats. Biological Conservation 142:1491-1499.

Mosandl, R., and A. Kleinert. 1998. Development of oaks (Quercus petraea (Matt.) Liebl.) emerged from bird-dispersed seeds under old-growth pine (Pinus silvestris L.) stands. Forest Ecology and Management 106:35-44.

Navarro-González, I., A. J. Pérez-Luque, F. J. Bonet, and R. Zamora. 2013. The weight of the past: land-use legacies and recolonization of pine plantations by oak trees. Ecological Applications 23:1267-1276.

Noss, R. F., J. F. Franklin, W. L. Baker, T. Schoennagel, and P. B. Moyle. 2006. Managing fire-prone forests in the western United States. Frontiers in Ecology and the Environment 4:481-487.

Pausas, J. G., C. Bladé, A. Valdecantos, J. P. Seva, D. Fuentes, J. A. Alloza, A. Vilagrosa, S. Bautista, J. Cortina, and R. Vallejo. 2004a. Pines and oaks in the restoration of Mediterranean landscapes of Spain: new perspectives for an old practice - a review. Plant Ecology 171:209-220.

Pausas, J. G., E. Ribeiro, and R. Vallejo. 2004b. Post-fire regeneration variability of Pinus halepensis in the eastern Iberian Peninsula. Forest Ecology and Management 203:251-259.

Pérez-Ramos, I. M., I. R. Urbieta, M. A. Zavala, and T. Marañón. 2012. Ontogenetic conflicts and rank reversals in two Mediterranean oak species: implications for coexistence. Journal of Ecology 100:467-477.

Peterson, D. L., J. K. Agee, G. H. Aplet, D. P. Dykstra, R. T. Graham, J. F. Lehmkuhl, D. S. Pilliod, D. F. Potts, R. F. Powers, and J. D. Stuart. 2009. Effects of timber harvest following wildfire in western North America. Gen. Tech. Rep. PNW-GTR 51. U.S. Department of Agriculture, Forest Service, Pacific Northwest Research Station, Portland, Oregon, USA.

Pons, J., and J. G. Pausas. 2007. Acorn dispersal estimated by radio-tracking. Oecologia 153:903-911.

Pons, J., and J. G. Pausas. 2008. Modelling jay (Garrulus glandarius) abundance and distribution for oak regeneration assessment in Mediterranean landscapes. Forest Ecology and Management 256:578-584.

Puerta-Piñero, C., J. M. Gómez, and F. Valladares. 2007. Irradiance and oak seedling survival and growth in a heterogeneous environment. Forest Ecology and Management 242:462-469.

Puerta-Piñero, C., A. Sánchez-Miranda, A. Leverkus, and J. Castro. 2010. Management of burnt wood after fire affects post-dispersal acorn predation. Forest Ecology and Management 260:345-352.

Pulido, F. J., and M. Díaz. 2005. Regeneration of a Mediterranean oak: a whole-cycle approach. Ecoscience 12: $92-102$.

Quero, J. L., A. Herrero, and R. Zamora. 2011. Linking stochasticity to determinism of woody plant recruitment in a mosaic landscape: a spatially explicit approach. Basic and Applied Ecology 12:161-171.

R Core Team. 2014. R: a language and environment for statistical computing. R Foundation for Statistical Computing, Vienna, Austria. http://www.R-project.org/.

Rey Benayas, J. M., L. Martínez-Baroja, L. Pérez-Camacho, P. Villar-Salvador, and K. D. Holl. 2015. Predation and aridity slow down the spread of 21-year-old planted woodland islets in restored Mediterranean farmland. New Forests 46:841-853. 
Rey Benayas, J. M., J. Navarro, T. Espigares, J. M. Nicolau, and M. A. Zavala. 2005. Effects of artificial shading and weed mowing in reforestation of Mediterranean abandoned cropland with contrasting Quercus species. Forest Ecology and Management 212:302-314.

Rost, J., P. Pons, and J. M. Bas. 2009. Can salvage logging affect seed dispersal by birds into burned forests? Acta Oecologica 35:763-768.

Ruiz-Benito, P., L. Gómez-Aparicio, and M. A. Zavala. 2012. Large-scale assessment of regeneration and diversity in Mediterranean planted pine forests along ecological gradients. Diversity and Distributions 18:1092-1106.

Schupp, E. W. 1995. Seed-seedling conflicts, habitat choice and patterns of plant recruitment. American Journal of Botany 82:399-409.

Schupp, E. W. 2007. The suitabilty of a site for seed dispersal is context-specific. Pages 445-462 in A. Dennis, E. Schupp, R. Green, and D. Westcott, editors. Seed dispersal. Theory and its application in a changing world. CAB International, Wallingford, UK.

Schupp, E. W., and M. Fuentes. 1995. Spatial patterns of seed dispersal and the unification of plant population ecology. Ecoscience 2:267-275.

Schupp, E. W., P. Jordano, and J. M. Gómez. 2010. Seed dispersal effectiveness revisited: a conceptual review. New Phytologist 188:333-353.
Valladares, F., and R. W. Pearcy. 2002. Drought can be more critical in the shade than in the sun: a field study of carbon gain and photo-inhibition in a Californian shrub during a dry El Niño year. Plant, Cell and Environment 25:749-759.

Valle, F., editor. 2003. Mapa de series de vegetación de Andalucía. Rueda, Madrid, Spain.

Van Ginkel, H. A. L., D. P. J. Kuijper, M. Churski, K. Zub, P. Szafrańska, and C. Smit. 2013. Safe for saplings not safe for seeds: Quercus robur recruitment in relation to coarse woody debris in Białowieża Primeval Forest, Poland. Forest Ecology and Management 304:73-79.

Ward, C., D. Pothier, and D. Paré. 2014. Do boreal forests need fire disturbance to maintain productivity? Ecosystems 17:1053-1067.

Wenny, D. G. 2000. Seed dispersal, seed predation, and seedling recruitment of a neotropical montane tree. Ecological Monographs 70:331-351.

Zamora, R., J. A. Hódar, L. Matías, and I. Mendoza. 2010. Positive adjacency effects mediated by seed disperser birds in pine plantations. Ecological Applications 20: 1053-1060.

Zavala, M. A., J. M. Espelta, and J. Retana. 2000. Constraints and trade-offs in Mediterranean plant communities: the case of Holm oak-Aleppo pine forests. Botanical Review 66: 119-149.

\section{SUPPORTING INFORMATION}

Additional supporting information may be found in the online version of this article at http://onlinelibrary.wiley.com/ doi/10.1002/ecy.1527/suppinfo 